\title{
Studi Proses Difusi melalui Membran dengan Pendekatan Kompartemen
}

\author{
Fransiska Retno Kuntari, Susatyo Pranoto, dan Adita Sutresno* \\ Program Studi Fisika, Fakultas Sains dan Matematika, Universitas Kristen Satya Wacana \\ Jl. Diponegoro 52-60, Salatiga 50711
}

\begin{abstract}
Intisari
Peristiwa difusi merupakan proses yang penting dalam kehidupan sehari-hari khususnya sistem dalam tubuh manusia. Dalam penelitian ini proses difusi dalam sistem tubuh manusia dipelajari dengan pendekatan kompartemen. Tujuan dari penelitian ini adalah meneliti pengaruh luas saluran, konsentrasi, dan koefisien difusi terhadap kecepatan difusi. Dua buah kompartemen berukuran masing-masing dibatasi oleh sebuah sekat berlubang yang merepresentasikan area dengan konsentrasi tinggi dan rendah, yang dihubungkan oleh suatu saluran. Dua buah sensor Conductivity Probe diletakkan pada masing-masing kompartemen dengan jarak yang sama terhadap sekat, dan dihubungkan dengan interface Vernier serta komputer yang terinstal Logger Lite1 9.4. Data konduktivitas dikonversikan menjadi konsentrasi, kemudian dianalisis. Model kompartemen dapat digunakan untuk mempelajari peristiwa difusi dalam sistem tubuh manusia. Laju difusi berbanding lurus terhadap luas saluran, konsentrasi, dan koefisien difusi.
\end{abstract}

\begin{abstract}
Diffusion is an important process in daily life, especially in the system of the human body. In this study, the diffusion process in human body system was studied using the compartments approach. The purpose of this study is to examine the effect of channel area, concentration, and diffusion coefficient on the rate of diffusion. Two compartments each sized were separated by a perforated barrier that represents areas of high and low concentrations, which were connected by a channel. Two Conductivity Probe sensors were placed in each compartment with the same distance to the barrierand were connected with a Vernier interface and a computer that hadLogger Lite 1.9.4 installed. The conductivity data is converted into concentration, then analyzed. The compartment model can be used to study diffusion process in the human body system. Diffusion rate is directly proportional to channel area, concentration and diffusion coefficient.
\end{abstract}

Keywords: compartments model, diffusion, human body system.

*Corresponding author: adita.sutresno@uksw.edu

http://dx.doi.org/10.12962/j24604682.v15i2.4617

2460-4682 @Departemen Fisika, FSains-ITS

\section{PENDAHULUAN}

Difusi adalah peristiwa perpindahan partikel dari lingkungan dengan konsentrasi tinggi menuju lingkungan dengan konsentrasi rendah $[1,2]$. Proses difusi menjadi proses yang penting pada sistem tubuh manusia, seperti pada difusi oksigen dan karbondioksida dalam sistem pernafasan, difusi $\mathrm{Ca}$ pada sinaps dalam sistem saraf, difusi beberapa molekul yang terjadi pada ginjal untuk mempertahankan homeostatis darah dalam sistem urinari [1], dan difusi zat (obat) dalam berbagai sistem tubuh manusia [3].

Berdasarkan Hukum Fick I, laju difusi dalam arah x sebanding dengan gradien konsentrasi [4], sedangkan menurut Hukum Fick II, perubahan konsentrasi terhadap waktu dalam daerah tertentu adalah sebanding dengan perubahan dalam perbedaan konsentrasi pada titik itu [5]. Besar arus difusi dinyatakan dalam Pers.(1) [6]:

$$
I=4 D s C_{\circ} N
$$

dengan I merupakan arus difusi (partikel/sekon), D merupakan koefisien difusi $\left(\mathrm{m}^{2} / \mathrm{s}\right)$, s merupakan luas saluran difusi $\left(\mathrm{m}^{2}\right), \mathrm{C}_{\circ}$ merupakan konsentrasi larutan $\left(\right.$ partikel $\left./ \mathrm{m}^{3}\right)$, dan $\mathrm{N}$ merupakan jumlah saluran [6].

Sebuah sistem fisiologi dapat diuraikan menjadi lebih sederhana dalam beberapa interaksi subsistem yang disebut dengan kompartemen. Perlu diketahui bahwa kompartemen dipahami sebagai material yang homogen, bukan sebagai suatu volum secara fisik, dan dapat pula terjadi pertukaran material antar kompartemen [7]. Pendekatan kompartemen ini digunakan untuk mempelajari peristiwa difusi dalam sistem tubuh manusia.

Penelitian ini menganalisis besaran-besaran pengaruh luas membran/saluran, gradien konsentrasi, dan koefisien difusi terhadap kecepatan difusi pada sistem tubuh manu- 


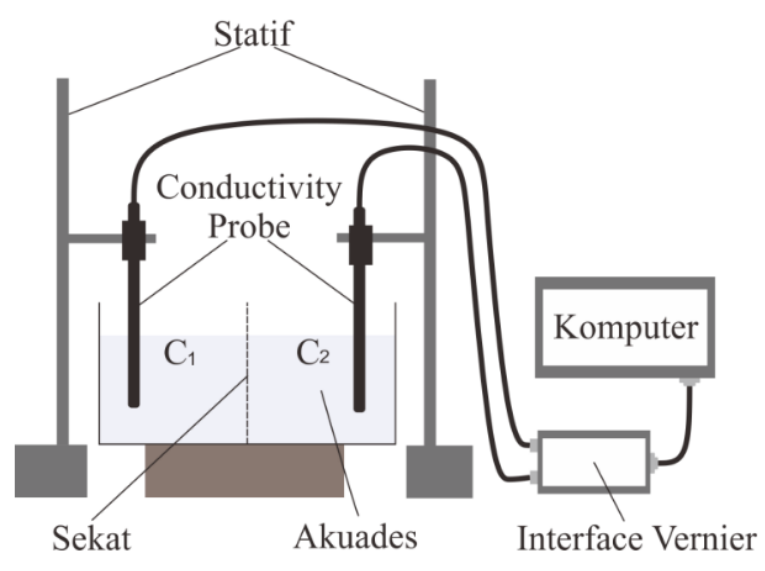

Gambar 1: Model eksperimen.

sia yang melibatkan membran semipermeabel dengan pendekatan kompartemen. Selain itu dapat diperoleh pula hubungan jumlah saluran terhadap $t_{0,25}$.

\section{METODOLOGI}

Model eksperimen yang digunakan dalam penelitian ini adalah berupa dua buah kompartemen, dengan kompartemen $\mathrm{C}_{1}$ merepresentasikan area yang berkonsentrasi tinggi dan kompartemen $\mathrm{C}_{2}$ merepresentasikan area yang berkonsentrasi rendah. Masing-masing kompartemen memiliki ukuran $5 \mathrm{~cm}$ $\times 5 \mathrm{~cm} \times 5 \mathrm{~cm}$. Di antara dua kompartemen terdapat sekat dengan jumlah lubang bervariasi dan berdiameter homogen 1 $\mathrm{mm}$ yang dapat dilewati oleh larutan yang kemudian disebut sebagai membran. Model eksperimen dibuat seperti Gambar 1.

Larutan akuades $100 \mathrm{ml}$ diberikan untuk setiap kompartemen, kemudian larutan yang diteliti dituangkan pada kompartemen $\mathrm{C}_{1}$. Perekaman data konsentrasi kompartemen $\mathrm{C}_{1}$ dan $\mathrm{C}_{2}$ menggunakan conductivity probe masing-masing diletakkan dengan jarak $4 \mathrm{~cm}$ dari sekat, kemudian dihubungkan dengan interface Vernier Lab Quest Mini dan komputer yang telah diinstal Logger Lite 1.9.4. Data konduktivitas yang diperoleh kemudian dikonversikan menjadi data konsentrasi yang diperoleh dari data look up table pada manual alat, kemudian dianalisis sehingga didapatkan distribusi partikel atau molekul untuk setiap parameter yang diteliti.

Untuk mendapatkan hasil pengaruh luas saluran terhadap kecepatan difusi dilakukan variasi jumlah lubang yaitu 200, 250, dan 400. Larutan yang digunakan adalah $\mathrm{NaCl}$ sebagai larutan utama dalam penelitian ini. $\mathrm{NaCl}$ adalah larutan yang banyak terdapat di dalam tubuh [1].

Untuk mendapatkan hasil pengaruh konsentrasi terhadap kecepatan difusi diberikan $\mathrm{NaCl}$ dengan variasi konsentrasi $1000 \mathrm{mg} / \mathrm{L}, 2000 \mathrm{mg} / \mathrm{L}$, dan $4000 \mathrm{mg} / \mathrm{L}$ pada kompartemen $\mathrm{C}_{1}$. Variasi konsentrasi tersebut diberikan dengan alasan agar mempermudah melihat pola dalam peristiwa difusi yang terjadi. Selain itu, dilakukan pembandingan terhadap larutan potassium $(\mathrm{KOH})$. Potasium juga terlibat dalam peristiwa di-

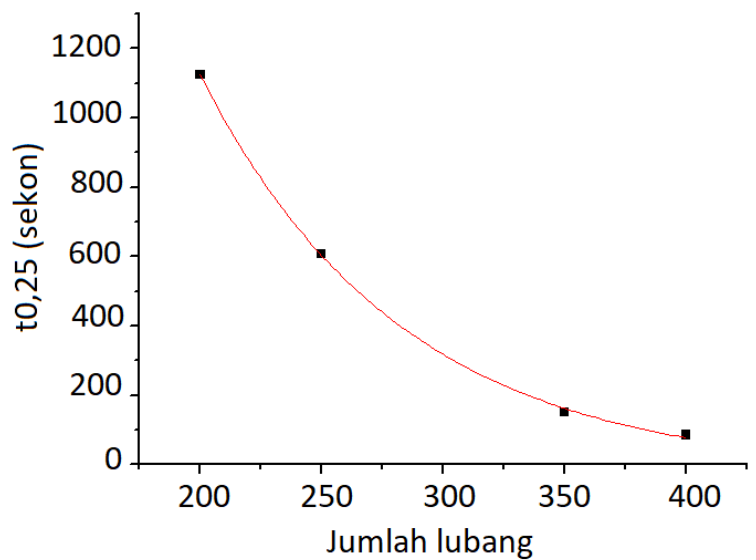

Gambar 2: Hubungan jumlah lubang membran terhadap $\mathrm{t}_{0,25}$ larutan $\mathrm{NaCl}$ konsentrasi $2000 \mathrm{mg} / \mathrm{L}$.

fusi pada sistem tubuh manusia [1].

Untuk mendapatkan hasil pengaruh koefisien difusi terhadap kecepatan difusi digunakan molekul $\mathrm{NaCl}$, kemudian dibandingkan dengan $\mathrm{KOH}$ dan $\mathrm{CaO}$.Kalsium terlibat dalam peristiwa difusi pada sistem tubuh manusia [8]. $\mathrm{NaCl}, \mathrm{KOH}$, dan $\mathrm{CaO}$ memiliki koefisien difusi berturut-turut $1,6 \times 10^{-5}$ $\mathrm{cm} / \mathrm{s}^{2} ; 2,67 \times 10^{-6} \mathrm{~cm} / \mathrm{s}^{2} ;$ dan $2,13 \times 10^{-8} \mathrm{~cm} / \mathrm{s}^{2}$ [9-11].

\section{HASIL DAN DISKUSI}

\section{Pengaruh luas saluran terhadap kecepatan difusi}

Gambar 2 menunjukkan distribusi $\mathrm{NaCl}$ konsentrasi untuk variasi jumlah lubang saluran 200, 250, dan 400. $\mathrm{t}_{0,25}$ adalah waktu yang dibutuhkan suatu larutan berkurang sebesar seperempat dari jumlah konsentrasi yang telah terdifusi ke tempat laindan dapat digunakan untuk memprediksi penurunan konsentrasi larutan [12]. Hasil eksperimen menunjukkan bahwa jumlah lubang berbanding lurus dengan luas saluran, sehingga semakin besar luas saluran, maka semakin cepat larutan mencapai jumlah seperempatnya, kemudian dari hasil curve fitting pada grafik Gambar 2, diperoleh bahwa terdapat hubungan eksponensial negatif antara jumlah lubang dan $\mathrm{t}_{0,25}$.

Jumlah lubang dikalikan luasan setiap lubang menunjukkan luas saluran.Semakin besar luas saluran, maka semakin besar arus difusi. Dalam penelitian ini semakin besar jumlah lubang maka semakin cepat penurunan konsentrasi yang terjadi, dengan persamaan $\mathrm{t}_{0,25}=12969,326 \mathrm{e}^{-N / 82,57868}-25,39556$ sekon (standard error dapat dilihat pada Gambar 2.). Semakin besar jumlah lubang, semakin besar pula arus difusi.Hal ini sesuai dengan dengan Hukum Fick 1 [6].

\section{Pengaruh konsentrasi terhadap kecepatan difusi}

Untuk pengaruh konsentrasi terhadap proses difusi, digunakan larutan $\mathrm{NaCl}$ dengan variasi konsentrasi. Hasilnya seperti pada Gambar 3. 


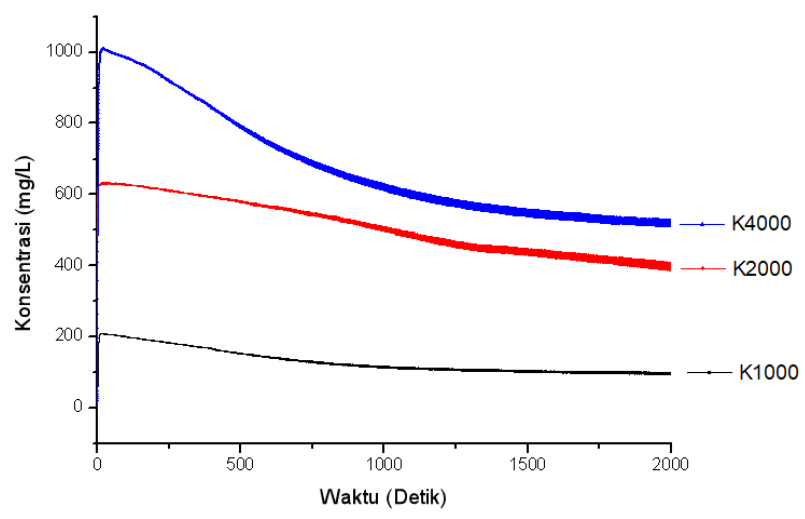

Gambar 3: Hubungan Konsentrasi terhadap Waktu untuk Lubang Membran 200 dengan Variasi Konsentrasi Awal Larutan $\mathrm{NaCl}$ (Kompartemen $\mathrm{C}_{1}$ ).

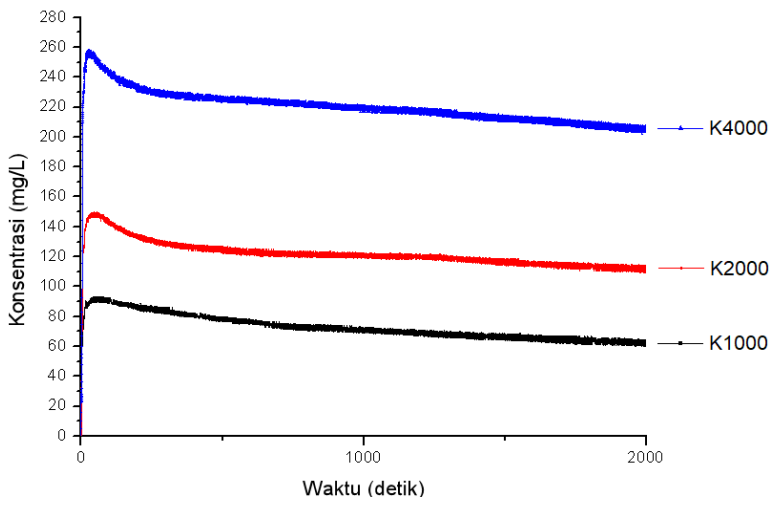

Gambar 4: Hubungan Konsentrasi terhadap waktu untuk lubang membran 200 dengan variasi konsentrasi awal larutan $\mathrm{KOH}$ (kompartemen $\mathrm{C}_{1}$ ).

Pada ketiga garis dalam Gambar 3 menunjukkan jumlah konsentrasi tertinggi yang berbeda, yaitu $1010 \mathrm{mg} / \mathrm{L}$ pada puncak garis biru, $633 \mathrm{mg} / \mathrm{L}$ pada puncak garis merah, dan $210 \mathrm{mg} / \mathrm{L}$ pada puncak garis hitam. Hal ini dikarenakan ketika konsentrasi pada kompartemen $\mathrm{C}_{1}$ mengalami pertambahan, secara bersamaan terjadi perpindahan konsentrasi ke kompartemen $\mathrm{C}_{2}$ karena adanya peristiwa difusi $[1,2]$. Diperoleh data kecepatan difusi untuk konsentrasi awal 1000, 2000, dan $4000 \mathrm{mg} / \mathrm{L}$ berturut-turut adalah 0,$0575 ; 0,1135$; dan 0,2410 $\mathrm{mg} / \mathrm{L}$. Hal ini menunjukkan kongruensi antara hasil simulasi dengan teori bahwa semakin besar perbedaan konsentrasi, maka semakin besar laju difusi $[6,13]$.

Dari data tersebut diperoleh bahwa untuk konsentrasi sebesar 2 kali dari semula, besar laju difusinya adalah 2,12 kali laju difusi dari konsentrasi tersebut. Secara umum, diperoleh hubungan yang sebanding antara I dan $\mathrm{C}_{\circ}$, yang sesuai dengan Pers.(1). Apabila dibandingkan dengan $\mathrm{KOH}$, hasilnya dapat dilihat pada Gambar 4.

Pada ketiga garis dalam Gambar 4 menunjukkan jumlah konsentrasi tertinggi yang berbeda, yaitu $258 \mathrm{mg} / \mathrm{L}$ pada puncak garis biru, $149 \mathrm{mg} / \mathrm{L}$ pada puncak garis merah, dan 88 $\mathrm{mg} / \mathrm{L}$ pada puncak garis hitam. Konsentrasi pada komparte-

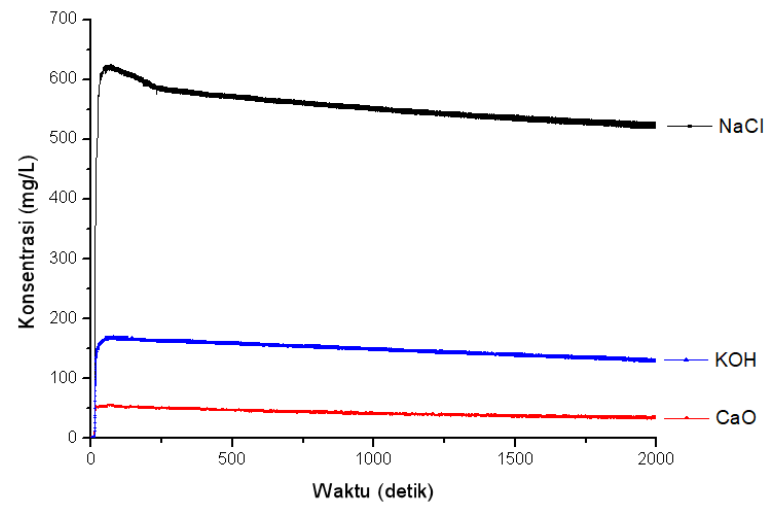

(a) Kompartemen $\mathrm{C}_{1}$

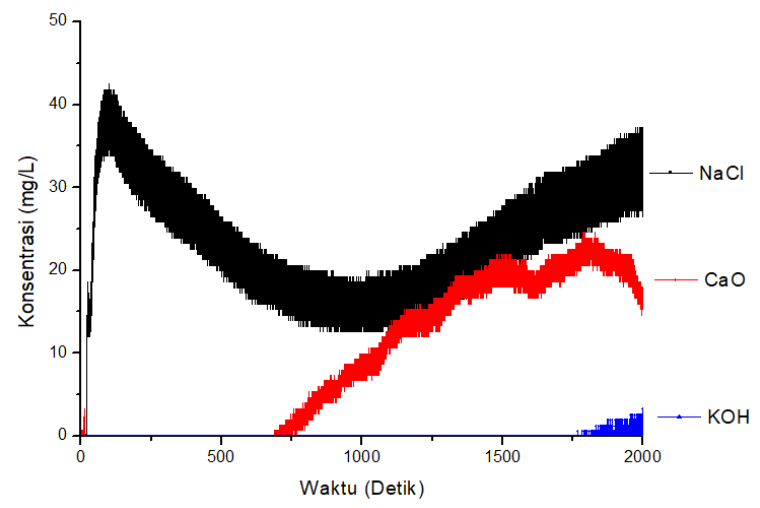

(b) Kompartemen $\mathrm{C}_{2}$

Gambar 5: Hubungan konsentrasi terhadap waktu untuk peristiwa difusi larutan $\mathrm{NaCl}$ (garis hitam), $\mathrm{KOH}$ (garis biru), dan $\mathrm{CaO}$ (garis merah) untuk konsentrasi 2000 dan lubang membran 300 .

men $\mathrm{C}_{1}$ mengalami pertambahan, sehingga secara bersamaan terjadi perpindahan konsentrasi ke kompartemen $\mathrm{C}_{2}$ karena adanya peristiwa difusi. Diperoleh data kecepatan difusi untuk konsentrasi awal 1000, 2000, dan $4000 \mathrm{mg} / \mathrm{L}$ berturutturut adalah 0,0138; 0,0190: dan 0,0265 (mg/L)/s.

Dapat disimpulkan bahwa untuk konsentrasi sebesar 2 kali dari semula, besar laju difusinya adalah 1,38 kali laju difusi dari konsentrasi tersebut. Secara umum, diperoleh hubungan yang sebanding antara I dan $\mathrm{C}_{\circ}$, yang sesuai dengan Pers.(1). Laju difusi $\mathrm{NaCl}$ lebih besar dibanding dengan $\mathrm{KOH}$.

\section{Pengaruh koefisien difusi terhadap kecepatan difusi}

Gambar 4 adalah grafik hubungan konsentrasi dan waktu untuk peristiwa difusi larutan $\mathrm{NaCl}, \mathrm{KOH}$, dan $\mathrm{CaO}$ untuk konsentrasi $2000 \mathrm{mg} / \mathrm{L}$ dan jumlah lubang 300.

Laju difusi $\mathrm{NaCl}, \mathrm{KOH}$, dan $\mathrm{CaO}$ berturut-turut adalah 0,053; 0,021; dan 0,011 (mg/L)/s, dan dari data tersebut diperoleh bahwa urutan besar laju difusi dari tinggi ke rendah adalah $\mathrm{NaCl}, \mathrm{KOH}$, dan $\mathrm{CaO}$. Urutan nilai koefisien difusi dari besar ke kecil adalah $\mathrm{NaCl}, \mathrm{KOH}$, dan $\mathrm{CaO}$ [10-12]. Hasil tersebut menunjukkan bahwa koefisien difusi sebanding dengan laju difusi. Hal ini sesuai dengan Hukum Fick I [5, 10]. 
TABEL I: Selisih konsentrasi ( kompartemen $\mathrm{C}_{1}$ dan $\mathrm{C}_{2}$ untuk larutan $\mathrm{CaO}, \mathrm{NaCl}$, dan $\mathrm{KOH}$.

\begin{tabular}{lccc}
\hline \hline Kompar- & $\Delta \mathrm{k}$ & $\Delta \mathrm{k}$ & $\Delta \mathrm{k}$ \\
temen & $\mathrm{NaCl}$ & $\mathrm{KOH}$ & $\mathrm{CaO}$ \\
\hline $\mathrm{C}_{1}$ & 140 & 67 & 30 \\
$\mathrm{C}_{2}$ & 131 & 75 & 7 \\
\hline \hline
\end{tabular}

Apabila perubahan konsentrasi pada kompartemen $\mathrm{C}_{1}$ dibandingkan dengan kompartemen $\mathrm{C}_{2}$, maka diperoleh data seperti yang ditunjukkan Tabel I.

Berdasarkan hasil penelitian, terdapat perbedaan selisih konsentrasi di kompartemen $\mathrm{C}_{1}$ dan $\mathrm{C}_{2}$ untuk setiap larutan. Hasil yang serupa juga diperoleh pada penelitian lain, dimana waktu yang lebih besar untuk molekul di kompartemen M mencapai titik puncak, dibanding molekul di kompartemen $\mathrm{L}$ mencapai titik 0. Dalam hal ini kompartemen L adalah kompartemen $\mathrm{C}_{1}$, sedangkan kompartemen $\mathrm{M}$ adalah komparte- men $\mathrm{C}_{2}$ [13]. Penurunan di $\mathrm{C}_{1}$ tidak otomatis sama dengan kenaikan di $\mathrm{C}_{2}$ pada posisi sensor yang dipasang karena masih memungkinkan proses molekul masih berjalan menuju sensor.

\section{SIMPULAN}

Hubungan jumlah lubang terhadap $\mathrm{t}_{0,25}$ adalah eksponensial negatif. Untuk larutan $\mathrm{NaCl}$ dengan konsentrasi 2000 $\mathrm{mg} / \mathrm{L}$ diperoleh persamaan $\mathrm{t}_{0,25}=12969,326 \mathrm{e}^{-N / 82,57868}$ 25,39556 sekon. Semakin besar jumlah lubang maka semakin besar laju difusi. Untuk konsentrasi sebesar 2 kali dari semula, besar laju difusi larutan $\mathrm{NaCl}$ adalah 2,12 kali laju difusi dari konsentrasi tersebut, sedangkan untuk larutan $\mathrm{KOH}$ sebesar 1,38 kali laju difusi dari konsentrasi tersebut. Laju difusi larutan yang berbeda dipengaruhi oleh koefisien difusi setiap larutan tersebut. Koefisien difusi $\mathrm{NaCl}>\mathrm{KOH}>\mathrm{CaO}$ sehingga laju difusi $\mathrm{NaCl}>\mathrm{KOH}>\mathrm{CaO}$.
[1] D.C. Rizzo, "Fundamentals of Anatomy Physiology" (Delmar, 2010).

[2] S. Trihandaru, A. Widyayanti, S. Rachmawati, and B.S. Toenlioe, "Pemodelan dan Pengukuran Difusi Larutan Gula dengan Lintasan Cahaya Laser", Prosiding Pertemuan Ilmiah XXVI HFI Jateng \& DIY, 2012.

[3] L. Miranti, "Pengaruh Konsentrasi Minyak Atsiri Kencur (Kaempfiria galangal L.) dengan basis Salep Larut Air terhadap Sifat Fisik Salep dan Daya Hambat Bakteri Staphylococcus aureus Secara In Vitro", Skripsi, Universitas Muhammadiyah Surakarta, Surakarta, 2009

[4] B. Haryanto, "Pengaruh Pemilihan Kondisi Batas, Langkah Ruang, Langkah Waktu dan Koefisien Difusi pada Model Difusi", Jurnal APLIKA, vol. 8, hlm. 1-7, 2008.

[5] Wati, P.B. Sastrowardoyo, "Difusi Cobalt dalam Na-Bentonit dan Ca-Bentonit", Jurnal Teknologi Pengelolaan Limbah, vol. 10, hlm. 53-61, 2007.

[6] H.C. Berg, "Randoms Walks in Biology: New and Expanded Edition", Princenton University Press., 1992.

[7] Introduction to Compartment Models, http://www.pmod.com/ files/ download/v31/doc/pkin/4614.htm

[8] M.J. Favus, D.A. Bushinsky, and J. Lemann, "Regulation of
Calcium, Magnesium, and Phospate Metabolism", American Society for Bone and Mineral Research, pp. 76-117, 2006.

[9] E.A. Guggenheim, "The Coefficient Diffusion of Sodium Chloride", Transactions of The Faraday Society, vol. 50, pp. 1048$1051,1954$.

[10] M.S. Bello, R. Rezzonico, and P.G. Righetti, "Use of TaylorAris Dispersion for Measurement of a Solute Diffusion Coefficient in Thin Capillaries", Science, vol. 266, pp. 773-776, 1994.

[11] R.H. Bogwardt, K.R. Bruce, and J. Blake, "An Investigation of Product-Layer Diffusivity for $\mathrm{CaO}$ Sulfation", American Chemical Society, vol. 26, pp. 1993-1998, 1987.

[12] E. Gepts, "Pharmacokinetic Concepts for TCI Anaesthesia", Anaesthesia, vol. 53, pp. 4-12, 1998.

[13] Adita Sutresno, "Difusi Kalsium dengan Media Kontras Gadolinium pada Sistem Sinapsis Menggunakan Simulasi Monte Carlo", Disertasi, 2019.

[14] A. Sutresno, F. Haryanto, S. Viridi, and I. Arif, "Investigation Monte Carlo Simulation for 3 Compartment Model as Biology System in Urinary", American Scientific Publishers, vol. 7, pp. 888-891, 2015. 